\title{
Identity Themes
}

Canada is a big country with a diverse population, and sometimes it's difficult for children to find their place in the world. School curricula address this in many ways, from Health programs that look at the importance of developing a positive personal identity, to Social Studies goals that examine community and the value of diversity, and English Language Arts materials that foreground thinking about the identity of self and others. Seeing ourselves in what we read is of immense importance, as are messages about diversity that challenge hegemonic ideas. Books dealing with identity themes build confidence in readers to be who we are, and help us imagine a world that's both authentic to reality and rich with new possibilities for the future.

Luckily for us, Canadian picture book authors and illustrators are increasingly tackling the subject of identity in ways that are meaningful and accessible to young folks. Many new titles include explorations of self-image with an emphasis on strategies to develop positive feelings about individual differences such as gender, race, ability, etc. Some of these books push directly against stereotypes, while others promote questions about social justice and deeper understandings of ourselves and other people.

In this chapter we introduce you to some of the best and most representative picture books with 2017-2019 copyright dates. It's longer than most of the other chapters because there were so many amazing titles to choose from that fit this theme! However, while we see various aspects of human experience presented, we also note that the variety of human abilities is a characteristic not fully recognised in terms of diversity in these books; we therefore encourage and look forward to the continued production of new, authentic writing that shows the whole range of humanity, with various abilities and exceptionalities included.

As with all of our thematic chapters, we have listed the books in our summary sections alphabetically, by author. Where not otherwise indicated, the name of the author(s) appears first under each title, and the illustrator last.

(C) BEVERLEY BRENNA, RICHARD DIONNE AND THERESA TAVARES, 2021 


\section{When I Found Grandma}

Saumiya Balasubramaniam

and Qin Leng

Maya longs to see her grandmother but when she arrives from far away, Grandma's not what her granddaughter expected. She wears a crimson sari and hands out treats that Maya hasn't tasted before. This compelling story about navigating cross-cultural contexts will support discussions on cultural identity. Saumiya Balasubramaniam's evocative first-person text is extended by Qin Leng's compelling illustrations in ink and watercolour. For ages $5^{-9}$.

\section{A Horse Named Steve Kelly Collier}

Steve is a horse who tries so hard to be special that at first he misses how unique he really is. With the fast pace, comic timing, and eye-catching ink and watercolour graphics shared by its sequel Team Steve, this book shows how important it is for young people to understand that no matter who they are, they have a unique identity all their own. For ages $3-8+$.

\section{Our Big Little Place}

James A. Conan

and Nicolle LaLonde

This title is about the life of a little boy who lives in a family apartment. His identity emerges as he plays with others and his imagination opens the door to a bigger world. This book is an exploration of home and community, delivered through James A. Conan's skillful storytelling and Nicolle LaLonde's eye-catching digital illustrations. For ages 4-8.

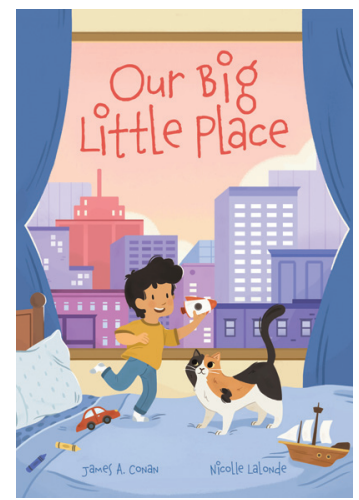


Through the Elephant's Door

Hélène de Blois

and France Cormier

Two friends go to the museum on a rainy day. Because of his size, Émile the elephant can't go through the same door as everyone else instead, he must go through the delivery door. During their time in the gallery, Émile receives continued scrutiny from one of the guards, offering a strong perspective on how terrible it feels to be negatively singled out. This is a book about equity and prejudice. For ages 5-12+.

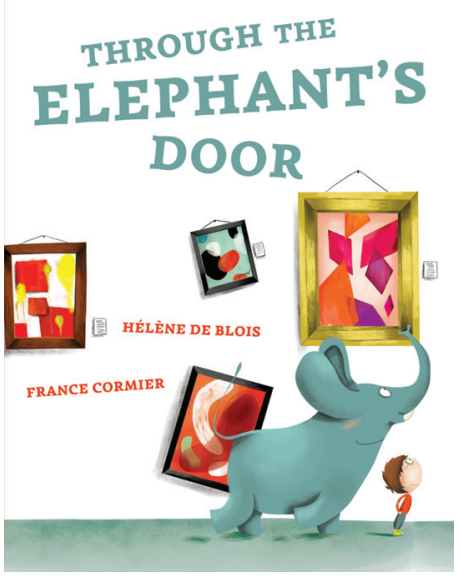

\section{Becoming Métis}

Deborah L. Delaronde-Falk

and Sheldon Dawson

At Métis Culture Days, Tiah experiences bannock making, snowshoe racing, moose calling, leg wrestling, samples pemmican, and learns about a number of other traditions including the reasons why Métis and Voyageurs would wear the culturally significant Sash. A clear message in this book involves the importance of exploring and learning about your culture. For ages 4-8.

\section{Love My Purse}

Belle DeMont

and Sonja Wimmer

Charlie, a young Black child, inherits a beautiful red purse from his grandmother and decides to wear it to school. Other people comment on his unusual choice, but over time his matter-of-fact responses are convincing, and the critics simply go about their daily business. Other characters see Charlie making choices for himself, and follow his lead.

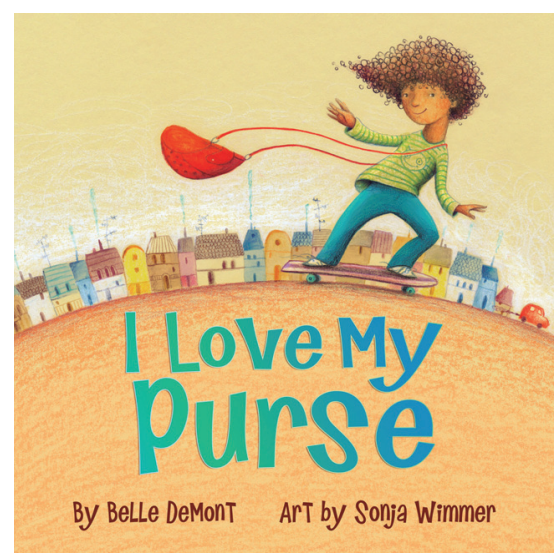
For ages $4-8$. 


\section{Swimming with Seals}

Maggie de Vries

and Janice Kun

This book is based on a true story about a child who lives with her grandmother and a great-aunt. When Ally flies to visit Aunt Kate at the seaside, she also connects with her birth mother, offering a chance for Ally to discover that she and her mom both love to swim. This book presents a good example of different kinds of families through Maggie de Vries' heartfelt narrative and Janice Kun's mixed-media illustrations that include collage, watercolour, drawing, and photography enhanced with Adobe Photoshop. For ages 5-9.

\section{Ben and the Scaredy-Dog \\ Sarah Ellis \\ and Kim LaFave}

Ben is afraid of dogs. An encounter with a nervous dog offers Ben a new perspective - that dogs can be frightened, too. This is a sensitive story about facing your fears and overcoming anxiety, enhanced by Kim LaFave's evocative use of paint, pencil and digital media. For ages 3-7.
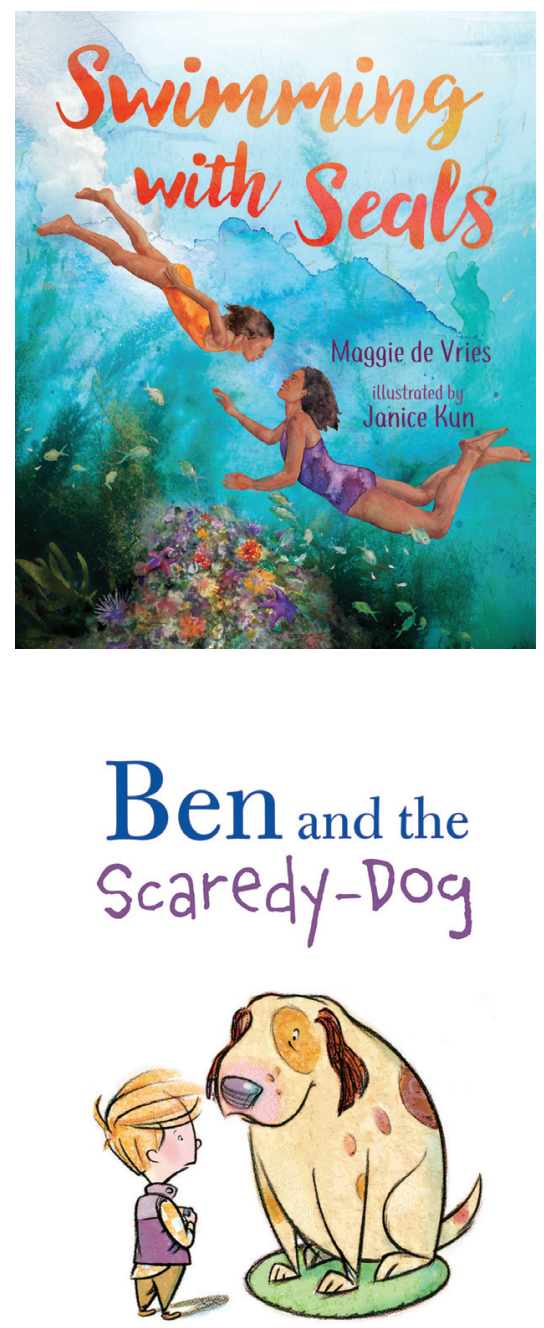

Written by Sarah Ellis Illustrated by Kim LaFave 


\section{Didn't Stand Up \\ Lucy Falcone \\ and Jacqueline Hudon}

This story narrates the experiences of a bystander who does not speak up against various bullying situations until the bullies attack closer to home. In response, everyone who has been bullied previously stands together in solid support. This book encourages taking action against injustice, and is based on an anti-Nazi protest poem written by Martin Niemöller. For ages 7-12+.

\section{The Reptile Club}

\section{Maureen Fergus}

and Elina Ellis

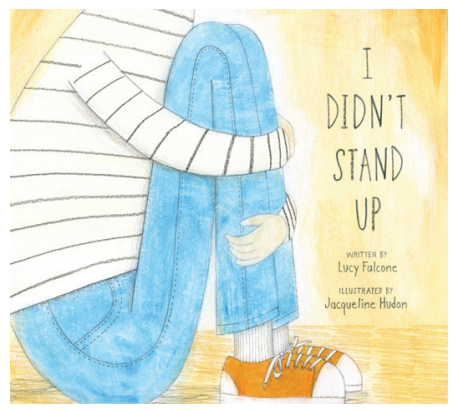

Rory is a boy who can't find a school club to match his interests and so he starts his own. While other children aren't initially interested, three talking reptiles volunteer, and eventually Rory's classmates come around. Adding to the theme of respecting various interests regardless of gender, there are depictions of dads making cookies, and boys knitting and joining ballet, all presented through lively, colourful illustrations. For ages 6-9.

\section{Trampoline Boy}

Nan Forler

and Marion Arbona

Identified by its publisher as a book about someone on the autism spectrum, this story follows a boy who likes to bounce on his trampoline all day, the youngsters who taunt him, and a girl who becomes his friend. With its lyrical, evocative text, enhanced by intriguing gouache and pencil illustrations, it could be a springboard for mature discussions about abilities. For ages 6-11.

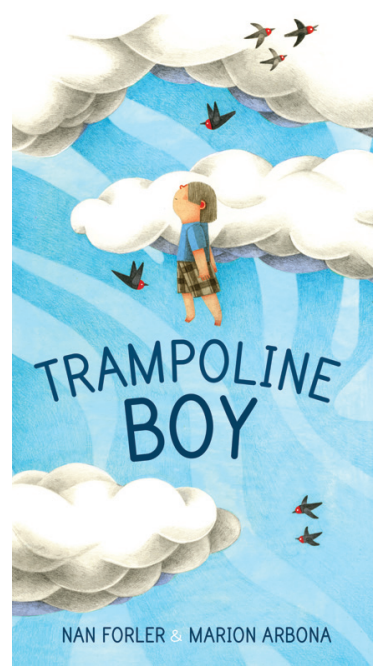




\section{Ho'onani: Hula Warrior \\ Heather Gale \\ and Mika Song}

Based on a true story, Ho'onani doesn't see herself as wahine (girl) or kane (boy) and she's happy to be in the middle. When she takes part in a school performance of a traditional kane hula chant, her sister is embarrassed until she sees Ho'onani's talent and stands up for her. This story unpacks issues about gender normativity and is based on the documentary A Place in the Middle. Watercolour and ink illustrations vividly render ideas about diversity and acceptance. For ages $5^{-12+.}$

\section{Fern and Horn}

\section{Marie-Louise Gay}

Fern and Horn are twins who look alike but have very different ways of seeing the world and being in the world. This book offers a lively text and colourful mixed-media illustrations to explore imagination and creativity as well as the fun that comes with originality. For ages $4-8$.

\section{The Walking Bathroom \\ Shauntay Grant \\ and Erin Bennett Banks}

Amayah wants to wear a truly original Halloween costume and relies on her imagination to help her break the norm - including a shower curtain cape and rolls of toilet paper worn like bracelets. Although her classmates are confused by her choices, she goes on to win the school contest. This is a book about unleashing your creativity and being proud of your uniqueness. For ages 4-8.

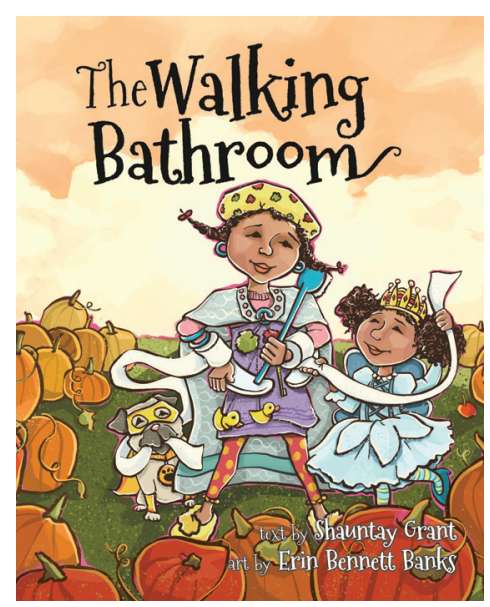




\section{The Cold Little Voice \\ Alison Hughes \\ and Jan Dolby}

This picture book follows a cold little voice as it speaks negative thoughts to a young narrator. A solution appears when the narrator starts hanging out with positive and accepting people. This is a story about being kind to ourselves. For ages $5^{-12+.}$

\section{Seamus's Short Story \\ Heather Hartt-Sussman \\ and Milan Pavlović}

Seamus longs to be taller. When he discovers his mother's high-heeled shoes, he can suddenly reach everything! Or can he? Clothes here become a simple means-to-an-end, and Seamus decides that there are definitely times to be tall and times to be short. A gently nuanced story about innovation, self-acceptance, and love, extended by Milan Pavlovićs colourful paintings of Seamus's world. For ages 4-8.
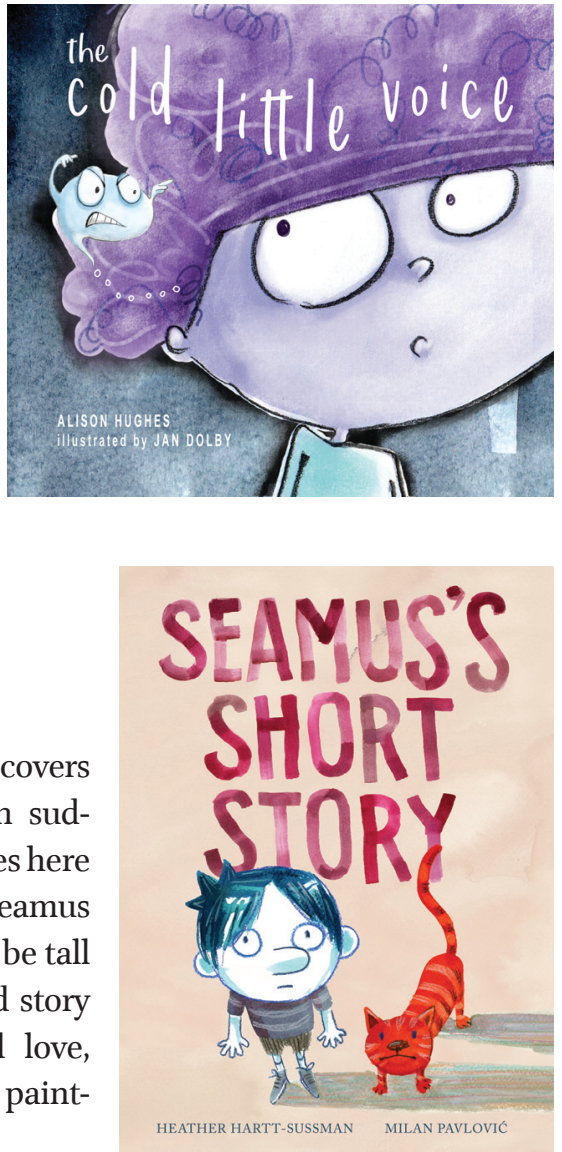

\section{Ira Crumb Feels the Feelings}

Naseem Hrab

and Josh Holinaty

Ira and Malcolm always play together but today they can't settle on an activity they both like. Ira is overcome with sadness when his friend goes off to play tag with the other children. Later, Ira shares his feelings and their friendship resumes. This is a book about how being friends doesn't mean you have to do everything together. For ages 4-7. 


\section{The Snuggly \\ Glen Huser \\ and Milan Pavlović}

Todd uses his baby sister's snuggly to carry his beloved teddy bear, and then discovers it's a great place to store all sorts of things until his collection bursts out all over the place during Show and Tell. This story offers a way to talk about changing roles within families when new siblings arrive, enhanced by Milan Pavlović's vibrant illustrations. For ages 2-7.

\section{What's My Superpower?}

AviaqJohnston

and Tim Mack

As Nalvana goes around town discovering the superpowers of other people, she learns about her own strengths in making others feel good about themselves. An Inuktitut glossary defines four words that are seamlessly integrated. This is a story about human differences and how communities rely on diversity. For ages $4-8$.

\section{Aunt Pearl}

Monica Kulling

and Irene Luxbacher

Aunt Pearl has been living homeless and comes to stay with Dan and Marta's family. She gathers things from trash bins and turns some of it into art. As fall approaches, Aunt Pearl becomes quieter and quieter, and eventually heads back out on her own. A story told without judgement or didacticism, this title offers the chance to think about mental health. Irene Luxbacher's elaborate collage illustrations are rich with visual clues. For ages 6-9+.
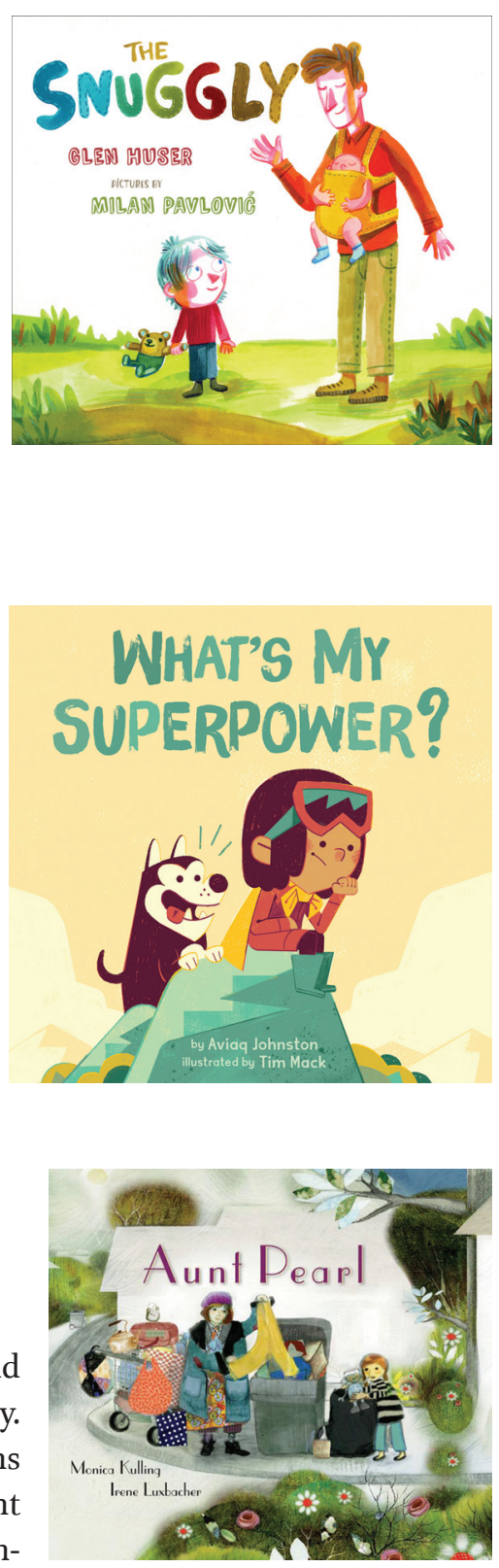


\section{A Pattern for Pepper}

Julie Kraulis

A young girl searches for the perfect dress as a special occasion draws near. With the help of a tailor, she learns about the cultural origins of various patterns depicted in unique illustrations using oils and graphite on board. This book presents clothes as a way to show one's personality. For ages 4-8.

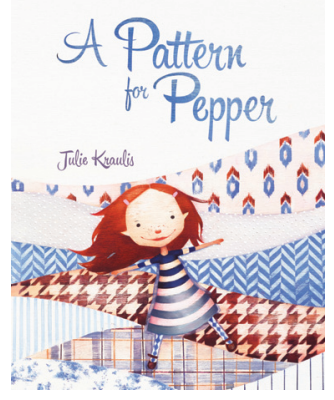

\section{Wallpaper}

Thao Lam

This is a wordless story, in Thao Lam's signature paper collage style, about a young girl too shy to play with others. After picking at the peeling wallpaper in her new room, she enters a fantastic imaginary world. When she returns to real life, she has developed new courage. This tale explores shyness and feelings of anxiety. For ages $5^{-8 .}$

\section{Goodnight, Hockey Fans}

Andrew Larsen

and Jacqui Lee

A young boy can't sleep because he longs to watch the hockey game; hearing the play-by-play on his radio allows him to relax and dream about a glorious game in which he himself scores the winning goal. Readers can be encouraged to think about the author's choice in simply calling the protagonist of this story "the boy" rather than giving him a name. Jacquie Lee's gouache illustrations, digitally edited, are visually interesting and generous with detail. For ages $3^{-8}$.

\section{Am Small \\ Qin Leng}

Mimi is unhappy about her size and lists the various inconveniences about being small before thinking about the possible advantages. When a baby sibling arrives, she relishes the chance to be a big sister. This is a book about coming to terms with one's own characteristics but also being open to new perspectives. Qin Leng's pen, ink and watercolour illustrations are simple yet poignant. For ages 4-7. 
The Muskox and the Caribou

Nadia Mike

and Tamara Campeau

Baby Muskox grows up with a different group, the Caribous. He feels like an outsider until he finds a herd that looks just like he does. As he joins them, he misses his Caribou mother, but looks forward to seeing where he belongs with the new group. This story reinforces the importance of cultural connections and self-

The Muskox the Caribou by Nadia Mike - illustrated by Tamara Campeau

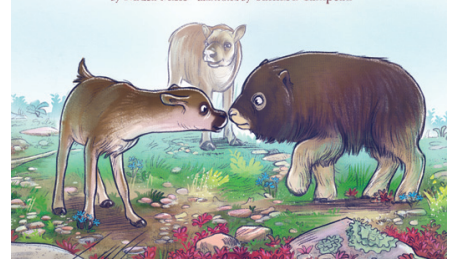
acceptance. For ages $5^{-9}$.

Moose's Roof

Jennifer Maruno

and Laurel Keating

Moose decides that living under a roof would be a good idea. With the help of friends, he creates a shelter carried on his antlers. Eventually he realises what works for others might not work for everyone, and celebrates being himself. For ages $5^{-8}$.

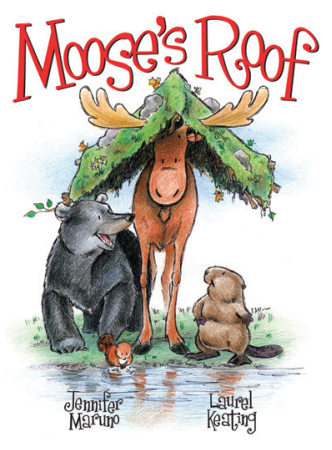

\section{Boonoonoonous Hair!}

Olive Senior

and Laura James

In this story, Jamilla learns to love her "fantabulous, splendiferous, boonoonoonous" hair. This is a book about self-acceptance and selflove. Laura James' boldly coloured pencil and paint illustrations truly enhance Olive Senior's empowering text. For ages 4-9.

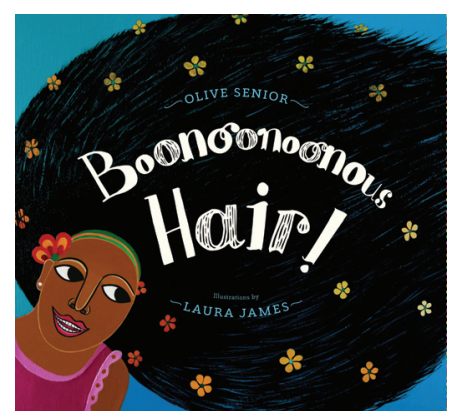




\section{Angus All Aglow \\ Heather Smith \\ and Alice Carter}

Angus loves sparkly things until his classmates laugh when he wears a glass bead necklace to school. One classmate who shares his interests supports him and Angus continues to fuel his inner sparkle. This is a story about individuality and the importance of acceptance. Alice Carter's watercolour, gouache, and pencil illustrations are sensitive and compelling. For ages $5^{-8}$.

\section{The Dog Who Wanted to Fly \\ Kathy Stinson \\ and Brandon James Scott}

Zora the dog wants to fly but after many failed attempts, she decides to give up. A friend in danger inspires her to even greater heights and... Zora soars to the rescue! This is a story about setting goals, naysayers, and never giving up. For ages 4-9.
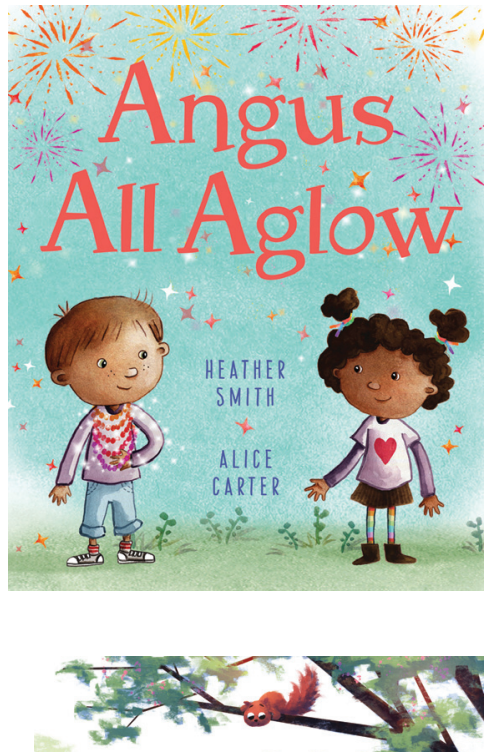

THE DOC

WHO WANTED

TO F LY
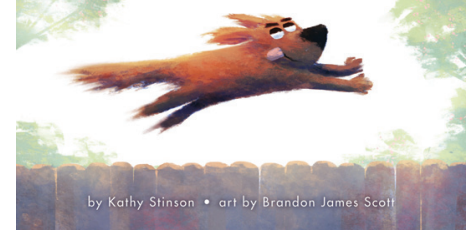

From the Stars in the Sky to the Fish in the Sea

Kai Cheng Thom,

Wai-Yant Li and Kai Yun Ching

Miu Lan is not just any child, but one who can change into any shape they can imagine. The only problem - according to the people they meet - is that they can't decide what to be: boy or girl; bird or fish; tree or star. But they find comfort in the arms of their mother, who sings of everlasting love and a steadfast belief that Miu Lan's courageous dreams about just being will come true. The message here is about learning to value uniqueness. For ages $3-7$. 


\section{I'm Finding My Talk}

Rebecca Thomas

and Pauline Young

Told in rhyming verse, this is a story about reuniting with culture taken away by the residential school system. The words and images identify activities like sewing regalia, dancing at powwow, and smudging as very helpful in the narrator's quest. It is a companion picture book to Rita Joe's I Lost My Talk. For ages 4-adult.

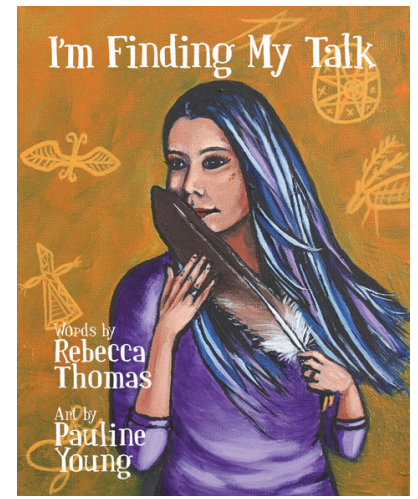

\section{The Sinking of Captain Otter}

Troy Wilson

and Maira Chiodi

Two kindred spirits - an otter and a butterfly - follow their dreams through an ocean voyage in spite of others' mockery about their differences. This book has important messages about acceptance and belonging. For ages $4-8$.

\section{Bibliography}

*In the spirit of the recommendations of the Truth and Reconciliation Commission, an asterisk appears beside works created by Indigenous writers or artists.

Collier, Kelly (2017). A Horse Named Steve. Toronto, ON: Kids Can Press.

Collier, Kelly (2018). Team Steve. Toronto, ON: Kids Can Press.

De Blois, Hélène (illustrated by France Cormier) (2019). Through the Elephant's Door. Victoria, BC: Orca Book Publishers.

de Vries, Maggie (illustrated by Janice Kun) (2018). Swimming with Seals. Victoria, BC:

Orca Book Publishers.

*Delaronde-Falk, Deborah L. (illustrated by Sheldon Dawson) (2018). Becoming Metis. Winnipeg, MB: Pemmican Publications.

DeMont, Belle (illustrated by Sonja Wimmer) (2017). I Love My Purse. Toronto, ON: Annick Press.

Ellis, Sarah (illustrated by Kim LaFave) (2018). Ben and the Scaredy-Dog. Toronto, ON: Pajama Press. 
Falcone, Lucy (illustrated by Jacqueline Hudon) (2019). I Didn't Stand Up. Keswick, ON: Clockwise Press.

Fergus, Maureen (illustrated by Elina Ellis) (2018). The Reptile Club. Toronto, ON: Kids Can Press.

Forler, Nan (illustrated by Marion Arbona) (2018). Trampoline Boy. Toronto, ON: Tundra Books/Penguin Random House.

Gale, Heather (illustrated by Mika Song) (2019). Ho'onani Hula Warrior. Toronto, ON: Tundra Books/Penguin Random House.

Gay, Marie-Louise (2019). Fern and Horn. Toronto, ON: Goundwood Books/House of Anansi Press.

Grant, Shauntay (illustrated by Erin Bennett Banks) (2017). The Walking Bathroom. Halifax, NS: Nimbus Publishing.

Hartt-Sussman, Heather (illustrated by Milan Pavlović) (2017). Seamus's Short Story. Toronto, ON: Groundwood Books/House of Anansi Press.

Hrab, Naseem (illustrated by Josh Holinaty) (2018). Ira Crumb Feels the Feelings. Toronto, ON: Owlkids Books.

Hughes, Alison (illustrated by Jan Dolby) (2019). The Cold Little Voice. Keswick, ON: Clockwise Press.

Huser, Glen (illustrated by Milan Pavlović) (2018). The Snuggly. Toronto, ON: Groundwood Books/House of Anansi Press.

*Johnston, Aviaq (illustrated by Tim Mack) (2017). What's My Superpower? Iqaluit, NU: Inhabit Media.

Kraulis, Julie. (2017). A Pattern for Pepper. Toronto, ON: Tundra Books/Penguin Random House.

Kulling, Monica (illustrated by Irene Luxbacher) (2019). Aunt Pearl. Toronto, ON: Groundwood Books/House of Anansi Press.

Lam, Thao (2018). Wallpaper. Toronto, ON: Owlkids Books.

Larsen, Andrew (illustrated by Jacquie Lee) (2017). Goodnight, Hockey Fans. Toronto, ON: Kids Can Press.

Leng, Qin (2018). I Am Small. Toronto, ON: Kids Can Press.

Maruno, Jennifer (illustrated by Laurel Keating) (2017). Moose's Roof. St. John's, NL: Breakwater Books.

*Mike, Nadia (illustrated by Tamara Campeau) (2017). The Muskox and the Caribou. Iqaluit, NU: Inhabit Media.

Balasubramaniam, Saumiya (illustrated by Qin Leng) (2019). When I Found Grandma. Toronto, ON: Groundwood Books.

Senior, Olive (illustrated by Laura James) (2019). Boonoonoonous Hair! Vancouver, BC: Tradewind Books.

Smith, Heather (illustrated by Alice Carter) (2018). Angus All Aglow. Victoria, BC: Orca Book Publishers. 
Stinson, Kathy (illustrated by Brandon James Scott) (2019). The Dog Who Wanted to Fly. Toronto, ON: Annick Press.

Thom, Kai Cheng (illustrated by Wal-Yant Li \& Kai Yun Ching) (2017). From the Stars in the Sky to the Fish in the Sea. Vancouver, BC: Arsenal Press.

*Thomas, Rebecca (illustrated by Pauline Young) (2019). I'm Finding My Talk. Halifax, NS: Nimbus Publishing.

Wilson, Troy (illustrated by Maira Chiodi) (2018). The Sinking of Captain Otter. Toronto, ON: Owlkids Books. 